\title{
Mechanisms of hyoscine butylbromide to improve adenoma detection: A case-control study of surface visualization at simulated colonoscope withdrawal
}

Authors

Institutions
James E. East ${ }^{1,2}$, Brian P. Saunders² ${ }^{2}$ David Burling ${ }^{3}$, Emily Tam ${ }^{4,5}$, Darren Boone ${ }^{4}$, Steve Halligan ${ }^{4}$, Stuart A. Taylor $^{4}$

Institutions are listed at the end of article.

\section{Bibliography}

Dol http://dx.doi.org/

10.1055/s-0034-1392771

Published online: 15.9.2015

Endoscopy International Open

2015; 03: E636-E641

(c) Georg Thieme Verlag KG

Stuttgart · New York

E-ISSN 2196-9736

\section{Corresponding author}

James E. East, FRCP

Translational Gastroenterology Unit

Experimental Medicine Division Nuffield Dept of Clinical Medicine

University of Oxford John Radcliffe Hospital Headley Way

Headington, Oxford, OX3 9DU

United Kingdom

Phone: +44 (0)1865 228753

Fax: +44 (0)1865 228763

james.east@ndm.ox.ac.uk
Background and study aims: Antispasmodics may improve mucosal visualization during colonoscope withdrawal, potentially improving polyp and adenoma detection. Meta-analysis and casecontrol studies suggest a $9 \%$ to $13 \%$ relative increase in adenoma and polyp detection. We aimed to assess the impact of hyoscine butylbromide on the expected visualization during colonoscope withdrawal using a CT colonography (CTC) simulation.

Patients and methods: Datasets from a previous CTC study examining the effect of antispasmodic were re-analyzed with customised CTC software, adjusted to simulate a standard colonoscopic view. Eighty-six patients received intravenous (IV) hyoscine butylbromide $20 \mathrm{mg}, 40 \mathrm{mg}$ or no antispasmodic. Main outcome measurements at unidirectional flythrough, simulating colonoscope withdrawal, were percentage colonic sur-

\section{Introduction}

In recent years, emphasis has been placed on colonoscopic quality, leading to reinvestigation of basic elements of colonoscopic extubation technique, such as withdrawal time, changing patient position, operator technique, and bowel preparation [1 -4], that have been shown to impact polyp and adenoma detection rates. Basic technique can be improved to maximize adenoma detection with minimal additional financial cost.

Routine use of antispasmodics during colonoscopy is controversial. Although the literature is inconsistent, in some studies, hyoscine butylbromide has been shown to accelerate colonoscopic intubation, and it may reduce patient procedural discomfort [5-7]. Other antispasmodics that have been investigated include glucagon, dicyclomine, hyoscyamine, atropine, peppermint oil, and warm water [8-14]. None of these has been shown to reduce intubation time, and only topical peppermint oil and warm water have been shown face visualization, numbers and sizes of unseen areas, and colonic length.

Results: Use of antispasmodic was associated with a significant relative increase in percentage surface visualization of $2.6 \%$ to $3.9 \%$, compared with no antispasmodic, $P<0.006$. Total numbers of missed areas and intermediate sized (300$1000 \mathrm{~mm}^{2}$ ) missed areas were significantly decreased, by approximately $20 \%$. There were no differences between the 20-mg and 40-mg doses. Mean colonic length $(161-169 \mathrm{~cm})$ was unchanged by antispasmodic.

Conclusions: IV hyoscine butylbromide at simulated colonoscope withdrawal was associated with significant increases in surface visualization, which might explain up to half the improvement in adenoma detection seen in clinical studies.

to reduce spasm scores or pain $[9,14]$. Until recently, very little investigation has been done of use of antispasmodics during the extubation or withdrawal phase of colonoscopy; however, the rationale for use of antispasmodics during extubation is not unreasonable. By reducing smooth muscle tone, haustral folds can be flattened, allowing better visualization of blind spots behind them, and peristaltic waves may be reduced, giving a still colonic surface on which to detect lesions. Indeed, studies using unblinding at CT colonography (CTC) suggest that most polyps missed by optical colonoscopy are on the back of folds in these blind spots [15]. A recent meta-analysis reported a relative risk for adenoma detection of 1.09 (95\% confidence interval $0.91-1.31)$ and for polyps of 1.13 (95\% CI $0.92-1.38$ ), numerically but non-significantly, in favor of hyoscine [16], and in a very large cohort study $(n=31088)$, the proportion of patients with at least one adenoma detected was $50.1 \%$ with hyoscine versus $44.5 \%$ without (relative increase $12.6 \%, P<0.001$ ) with 
similar improvements for advanced adenoma detection rates [17]. This pair of estimates suggests that the relative improvement in adenoma detection rate is likely to be on the order of $9 \%$ to $3 \%$.

Despite the theoretical advantages of routine use of antispasmodics and expert recommendation, implementation has been variable worldwide. In a United Kingdom national colonoscopy audit, for example, only $20 \%$ of colonoscopists used antispasmodics routinely [18]. In the United States and France, hyoscine butylbromide is unlicensed for colonoscopy. Furthermore, use of antispasmodics is not recommended in the US multi-society taskforce guidelines on quality in colonoscopic technique [19]; however, the converse is true in Japan, where usage is routine. Hyoscine butylbromide is the antispasmodic most commonly used during colonoscopy. Data from the CTC and barium enema literature suggest that it is superior to both glucagon and placebo in improving colonic distension and diagnostic quality [20-22]. Assessing the effect of hyoscine butylbromide on mucosal visualization during colonoscopic extubation is technically very challenging. However, recently developed, customized CTC software is able to calculate the amount of colonic surface seen during simulated colonoscope withdrawal, corrected for the field of view of a modern colonoscope, as we have previously reported [23].

The purpose of our study was to approximate the changes in percentage surface visualization, numbers and sizes of missed areas, and changes in colonic length that are likely to be encountered with intravenous (IV) hyoscine butylbromide when colonoscopy is simulated by CTC in patients suspected of having colorectal cancer. Given that this is a simulation of colonoscopic withdrawal, the study results should be viewed cautiously; however, they may give some insight into the mechanism by which hyoscine appears to improve adenoma detection in clinical studies.

\section{Patients and methods}

The protocol for the original CTC study was approved by our Local Regional Ethics Committee and all patients gave written informed consent. Specific permission for this additional analysis was sought from and granted by the same Ethics Committee.

\section{CTC dataset selection and spasmolytic administration} CTC datasets were collated from a previous randomized trial assessing the effect of hyoscine butylbromide on colonic distension at CTC in 136 patients. All patients were clinically suspected of having colorectal cancer. The methods used in the previous CTC study have been reported in detail elsewhere and are described briefly below. [21]

The first 20 patients received $20 \mathrm{mg}$ hyoscine butylbromide (Buscopan; Boehringer Ingelheim, Bracknell, England) IV given just before colonic gas insufflation (see below). Thereafter patients were randomised to receive either no antispasmodic or a slow bolus of $20 \mathrm{mg}$ (given as before) or $40 \mathrm{mg}$ of hyoscine butylbromide. If patients were randomised to $40 \mathrm{mg}, 20 \mathrm{mg}$ was given before the colonic gas insufflation in the prone position (performed first) and then an additional $20 \mathrm{mg}$ was given before the supine scan (performed immediately after the prone scan). Therefore, only supine datasets reflect the full 40-mg dosage for those randomised to $40 \mathrm{mg}$. Contraindications to antispasmodic were recently symptomatic ischemic heart disease and a history of closed-angle glaucoma. Three patients originally randomized to the antispasmodic group had contraindications and were as- signed to the no antispasmodic group. Minimization was used to balance the groups as accrual progressed. In total, 40 patients received no antispasmodic, 66 received $20 \mathrm{mg}$, and 30 received $40 \mathrm{mg}$ hyoscine butylbromide. Due to data loss, data corruption, or inadvertent destruction, only 86 of the original 136 datasets were available for the current study, 33 without antispasmodic, 35 assigned to $20 \mathrm{mg}$, and 18 assigned to $40-\mathrm{mg}$ hyoscine butylbromide.

\section{CTC protocol}

All patients underwent colonic insufflation of carbon dioxide via manual compression of a previously filled enema bag, until approximately $2500 \mathrm{~mL}$ had been introduced or to the limit of patient tolerance. Gas was introduced via either a thin rectal tube or a rectal balloon catheter, with allocation via a separate randomization sequence. Patients were scanned initially in the prone position. After this, those who were allocated to $40 \mathrm{mg}$ hyoscine had further administration as described above. All patients then had additional gas introduced via the rectal catheter to account for carbon dioxide absorption during the prone scan. Scout scans were used before data acquisition in each position to determine if distension was adequate.

\section{CTC dataset analysis}

The 86 datasets were analysed with customized proprietary CTC software (V3 D colon; Viatronix, Stonybook, NY) by a gastroenterologist who had received formal training in CTC examination (over 40 endoscopically validated datasets) and had experience with the software functionality. The technique has been described previously [23]. In brief, the software automatically segments gas-filled colon from surrounding organs and calculates a centerline within the segmented lumen from the anal verge to the cecum, facilitating automated 3-dimensional (3D) endoluminal navigation ( $\bullet$ Fig. 1 a). The user is able to check the segmentation via a $3 \mathrm{D}$ colon map and adjust if necessary. The software tracks the amount of colonic surface within the field of view during automated endoluminal navigation and calculates the amount of visualized colonic surface area (expressed as a percentage of the whole colonic surface), and the number, size, and distance from the anal verge of all missed areas (i.e., areas of unseen colonic surface) [24]. The visualized surface is "painted" green by the software, thus indicating missed areas to the observer ( Fig. $\mathbf{1 b}$ ). Total colonic length is also reported automatically, calculated via the centreline.

Customization of the software for the purposes of the current study allowed the observer to vary the field of view of the endoluminal "camera" from 0 to 180 degrees, and to download missed area data onto a computer spreadsheet.

The observer then performed an automated flythrough without detours along the software-determined centerline, with the virtual camera facing the cecum, equivalent to the view during optical colonoscope withdrawal. The field of view was set to 140 degrees for the current study, specifically to simulate a standard, optical colonoscope. The observer performed the flythrough on both prone and supine series from all 86 CTC datasets, recording percentage mucosal visualization, number of missed areas [total, intermediate sized $\left(300-1000 \mathrm{~mm}^{2}\right)$, and large $\left.\left(>1000 \mathrm{~mm}^{2}\right)\right]$, and total colonic length. 

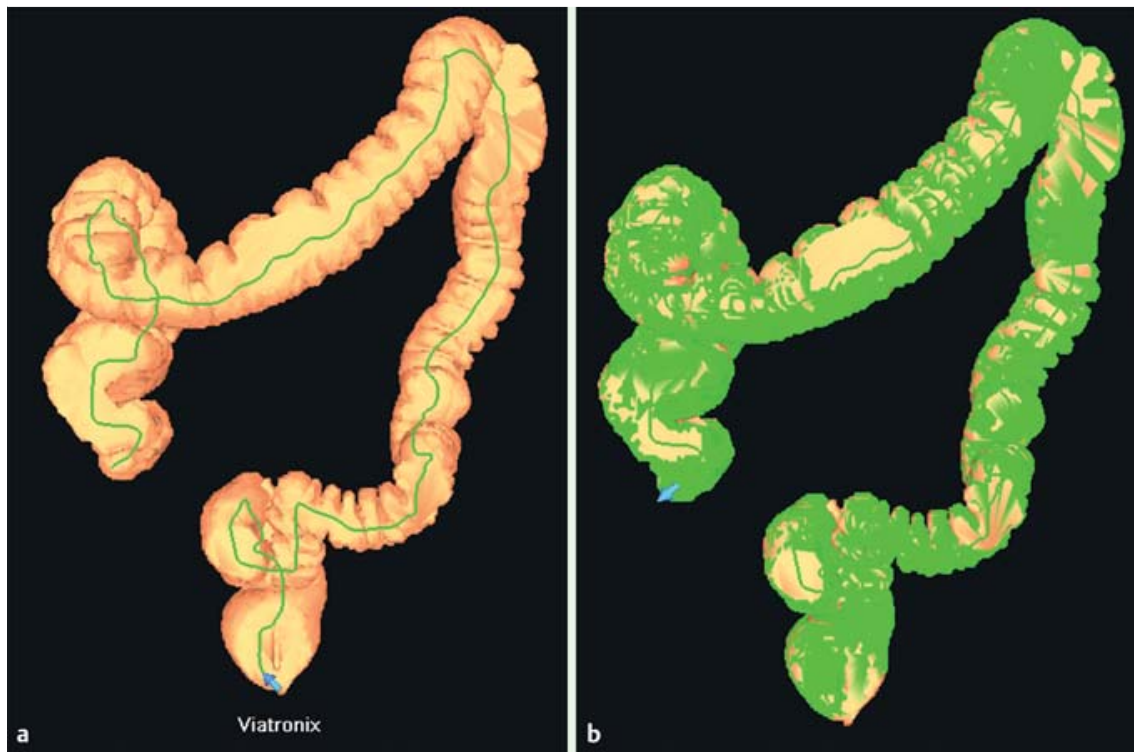

Fig. 1 a Overview of the colon with centerline for navigation (green) automatically drawn by the CT colonography software. $\mathbf{b}$ Overview after unidirectional 3D-endoluminal flythrough facing the cecum, where the software had "painted" visualized areas green. Unseen areas remain beige.

\section{Statistical analysis}

The primary outcome measure was the percentage surface visualization achieved in patients receiving either no antispasmodic or antispasmodic. The supine position was chosen for analysis because it was felt to give the best distension overall, particularly in the transverse colon, and of the two available options (supine or prone), was felt to best model usual patient position during colonoscopy. Age, percentage colonic surface visualization, missed areas, and colonic length were compared between the two groups using unpaired, 2-tailed, t-tests. Sex ratios and use of a rectal balloon catheter were compared with Fisher's exact test. Further data analyses were performed for a split by dose of antispasmodic. Probability values were considered significant at the $5 \%$ level and $P$ values $\geq 0.05$ but $<0.1$ were considered to indicate a statistical trend.

\section{Results}

$\nabla$

Datasets $(n=86)$ were initially split into those who had received antispasmodic (either $20 \mathrm{mg}$ or $40 \mathrm{mg}, \mathrm{n}=53$ ) and those who had not $(n=33)(-$ Table 1$)$. There were no significant differences in age, sex ratio, or use of rectal balloon catheter between the two groups. When antispasmodic was used, there was a highly significant relative increase in the total colonic surface visualized (2.6 and 3.9\% for prone and supine datasets, respectively), equivalent to relative reductions in percentage surface unseen of $18 \%$ and $25 \%$ ( Table 1 ).

The total number of missed areas of any size was reduced significantly by antispasmodic, from approximately 90 missed areas to just over 65 (28\% relative reduction). When the missed areas were subclassified by size, there was a significant reduction in intermediate-size $\left(300-1000 \mathrm{~mm}^{2}\right)$ missed areas in the supine position, and a trend toward reduction in the prone position, from approximately 25 to 20 (20\% relative reduction) missed areas. There were no significant differences in the numbers of large $\left(>1000 \mathrm{~mm}^{2}\right)$ missed areas ( $\bullet$ Table $\left.\mathbf{1}\right)$.

No significant difference in total colonic length was seen with antispasmodic, with an overall length of between 160 and $170 \mathrm{~cm}$. Colonic lengths ranged from 110 to $247 \mathrm{~cm}$, with 6 $(11 \%)$ and $3(6 \%)$ colons being longer than $200 \mathrm{~cm}$ in the prone and supine positions, respectively, in the antispasmodic group versus $3(9 \%)$ and $2(6 \%)$, respectively, in the group that received no antispasmodics ( $\bullet$ Table 1 ).

The supine dataset was then divided into three groups: Those who received no antispasmodic $(n=33)$, those who received $20 \mathrm{mg}(\mathrm{n}=35)$, and those who received $40 \mathrm{mg}(\mathrm{n}=18)$ ( Table 2). Again significant increases were seen in total colonic visualization for both $20 \mathrm{mg}$ and $40 \mathrm{mg}$ compared with no antispasmodic, with effect sizes similar to those seen in the antispasmodic versus no antispasmodic analysis. There was, however, no significant difference for any of the parameters tested when the 20-mg and 40-mg groups were compared. Similarly there were significant reductions or there was a trend toward significance for reduction in total missed areas and intermediate $\left(300-1000 \mathrm{~mm}^{2}\right)$ sized missed areas between the no-antispasmodic group and both the $20-\mathrm{mg}$ and $40-\mathrm{mg}$ groups, but not between the $20-\mathrm{mg}$ and $40-\mathrm{mg}$ groups ( Table 2 ). There were no significant differences in the numbers of large $\left(>1000 \mathrm{~mm}^{2}\right)$ missed areas or in colonic length among any of the groups.

\section{Discussion \\ $\nabla$}

\section{Principal findings}

This study suggests that use of hyoscine butylbromide increases the relative percentage of colonic surface visualized at simulated colonoscope withdrawal by approximately $4 \%$. There were also significant relative decreases of approximately $20 \%$ in both the total number of missed areas and the intermediate-sized (300$1000 \mathrm{~mm}^{2}$ ) missed areas with the use of antispasmodic. A reduction in intermediate-sized missed areas may be important clinically because these areas might harbor a small $(6-9 \mathrm{~mm})$ or diminutive $(\leq 5 \mathrm{~mm})$ polyp. There was little difference between prone and supine positioning; however, supine data are preferred to represent the best simulation of optical colonoscopy as the best distension is achieved, because the transverse colon can be collapsed in the prone position at CT colonography [23]. Furthermore, prone positioning is rarely used during the withdrawal phase of colonoscopy [2].

Colorectal length was not significantly altered by antispasmodic. Total colonic length was $169 \mathrm{~cm}$ when prone and $161 \mathrm{~cm}$ in 


\begin{tabular}{|c|c|c|c|c|}
\hline & \multirow[t]{2}{*}{ Position } & \multicolumn{2}{|c|}{ Hyoscine butylbromide IV } & \multirow[t]{2}{*}{$P$ value } \\
\hline & & No $(n=33)$ & Yes $(n=53)^{1}$ & \\
\hline \multirow{2}{*}{\multicolumn{2}{|c|}{ Age, years }} & $65.8 \pm 11.0$ & $62.2 \pm 12.4$ & \multirow[t]{2}{*}{0.16} \\
\hline & & $(41-89)$ & $(34-85)$ & \\
\hline $\begin{array}{l}\text { Sex, male/ } \\
\text { female (\%) }\end{array}$ & & $13(39 \%)$ & $28(53 \%)$ & $0.27^{2}$ \\
\hline $\begin{array}{l}\text { Balloon } \\
\text { catheter (\%) }\end{array}$ & & $17(52 \%)$ & $29(55 \%)$ & $0.83^{2}$ \\
\hline \multirow[t]{2}{*}{$\begin{array}{l}\% \text { colonic surface } \\
\text { visualization }\end{array}$} & Prone & $\begin{array}{l}87.3 \pm 3.9 \\
(77-95)\end{array}$ & $\begin{array}{l}89.6 \pm 3.6 \\
(78-95)\end{array}$ & 0.005 \\
\hline & Supine & $\begin{array}{l}86.4 \pm 4.3 \\
(75-95)\end{array}$ & $\begin{array}{l}89.8 \pm 3.3 \\
(78-96)\end{array}$ & $<0.001$ \\
\hline \multirow[t]{2}{*}{$\begin{array}{l}\text { Total number } \\
\text { missed areas }\end{array}$} & Prone & $\begin{array}{l}87.9 \pm 30.7 \\
(25-157)\end{array}$ & $\begin{array}{l}65.6 \pm 26.3 \\
(22-178)\end{array}$ & 0.002 \\
\hline & Supine & $\begin{array}{l}89.0 \pm 34.8 \\
(28-156)\end{array}$ & $\begin{array}{l}68.6 \pm 27.7 \\
(22-159)\end{array}$ & 0.011 \\
\hline \multirow[t]{2}{*}{$\begin{array}{l}\text { Missed areas } \\
300-1000 \mathrm{~mm}^{2}\end{array}$} & Prone & $\begin{array}{l}24.6 \pm 10.2 \\
(6-55)\end{array}$ & $\begin{array}{l}20.2 \pm 10.8 \\
(6-75)\end{array}$ & 0.091 \\
\hline & Supine & $\begin{array}{l}25.5 \pm 12.5 \\
(8-54)\end{array}$ & $\begin{array}{l}19.6 \pm 10.1 \\
(7-62)\end{array}$ & 0.044 \\
\hline \multirow[t]{2}{*}{$\begin{array}{l}\text { Missed areas } \\
>1000 \mathrm{~mm}^{2}\end{array}$} & Prone & $\begin{array}{l}6.8 \pm 4.8 \\
(1-20)\end{array}$ & $\begin{array}{l}7.0 \pm 5.1 \\
(2-33)\end{array}$ & 0.64 \\
\hline & Supine & $\begin{array}{l}7.2 \pm 5.9 \\
(1-28)\end{array}$ & $\begin{array}{l}6.6 \pm 4.3 \\
(0-23)\end{array}$ & 0.73 \\
\hline \multirow[t]{2}{*}{$\begin{array}{l}\text { Total colonic } \\
\text { length, } \mathrm{cm}\end{array}$} & Prone & $\begin{array}{l}168.8 \pm 20.3 \\
(133.4-222.0)\end{array}$ & $\begin{array}{l}166.9 \pm 28.0 \\
(115.0-246.7)\end{array}$ & 0.73 \\
\hline & Supine & $\begin{array}{l}161.3 \pm 25.2 \\
(109.9-231.2)\end{array}$ & $\begin{array}{l}161.3 \pm 26.3 \\
(106.7-212.4)\end{array}$ & 1.00 \\
\hline
\end{tabular}

Table 1 Surface visualization, missed areas, and colonic length with antispasmodic versus no antispasmodic.

Data presented as mean \pm standard deviation (range).

$120 \mathrm{mg}$ or $40 \mathrm{mg}$ hyoscine

${ }^{2}$ Fisher's exact test

Table 2 Results for varying doses of antispasmodic, supine position.

\begin{tabular}{|c|c|c|c|c|c|c|}
\hline \multirow[t]{2}{*}{ Variable } & \multicolumn{3}{|c|}{ Hyoscine Butylbromide IV } & \multicolumn{3}{|l|}{$P$ value } \\
\hline & $\begin{array}{l}\mathrm{Nil}^{1} \\
(\mathrm{n}=31)\end{array}$ & $\begin{array}{l}20 \mathrm{mg}^{1} \\
(\mathrm{n}=34)\end{array}$ & $\begin{array}{l}40 \mathrm{mg}^{1} \\
(\mathrm{n}=14)\end{array}$ & Nilvs $20 \mathrm{mg}$ & Nil vs $40 \mathrm{mg}$ & 20 vs $40 \mathrm{mg}$ \\
\hline Age, years & $\begin{array}{l}65.5 \pm 10.3 \\
(41-81)\end{array}$ & $\begin{array}{l}61.7 \pm 13.1 \\
(34-85)\end{array}$ & $\begin{array}{l}64.2 \pm 9.8 \\
(45-83)\end{array}$ & 0.20 & 0.68 & 0.48 \\
\hline Sex, male (\%) & $12(39 \%)$ & $15(44 \%)$ & $9(64 \%)$ & $0.80^{2}$ & $0.34^{2}$ & $0.20^{2}$ \\
\hline Balloon catheter (\%) & $16(52 \%)$ & $18(53 \%)$ & $7(50 \%)$ & $1.0^{2}$ & $1.0^{2}$ & $1.0^{2}$ \\
\hline $\begin{array}{l}\text { \% Colonic surface } \\
\text { visualization }\end{array}$ & $\begin{array}{l}86.4 \pm 4.3 \\
(75-95)\end{array}$ & $\begin{array}{l}89.6 \pm 3.6 \\
(78-95)\end{array}$ & $\begin{array}{l}90.4 \pm 2.6 \\
(84-95)\end{array}$ & 0.002 & $<0.001$ & 0.43 \\
\hline $\begin{array}{l}\text { Total number } \\
\text { missed areas }\end{array}$ & $\begin{array}{l}89.0 \pm 34.8 \\
(28-156)\end{array}$ & $\begin{array}{l}68.7 \pm 29.3 \\
(22-159)\end{array}$ & $\begin{array}{l}72.5 \pm 24.3 \\
(40-114)\end{array}$ & 0.011 & 0.081 & 0.40 \\
\hline $\begin{array}{l}\text { Missed areas } \\
300-1000 \mathrm{~mm}^{2}\end{array}$ & $\begin{array}{l}25.5 \pm 12.5 \\
(8-54)\end{array}$ & $\begin{array}{l}20.0 \pm 11.5 \\
(8-62)\end{array}$ & $\begin{array}{l}18.8 \pm 6.3 \\
(7-26)\end{array}$ & 0.071 & 0.023 & 0.97 \\
\hline $\begin{array}{l}\text { Missed areas } \\
>1000 \mathrm{~mm}^{2}\end{array}$ & $\begin{array}{l}7.2 \pm 5.9 \\
(1-28)\end{array}$ & $\begin{array}{l}6.2 \pm 4.3 \\
(1-23)\end{array}$ & $\begin{array}{l}7.7 \pm 4.4 \\
0-16\end{array}$ & 0.45 & 0.76 & 0.35 \\
\hline $\begin{array}{l}\text { Total colonic } \\
\text { length, cm }\end{array}$ & $\begin{array}{l}161.3 \pm 25.2 \\
(109.9-231.2)\end{array}$ & $\begin{array}{l}158.3 \pm 28.3 \\
(106.7-212.4)\end{array}$ & $\begin{array}{l}164.9 \pm 18.3 \\
(135.1-193.0)\end{array}$ & 0.66 & 0.59 & 0.35 \\
\hline
\end{tabular}

Data presented as mean \pm standard deviation (range).

1 Supine scans unavailable for all patients leading to a reduced number of datasets for analysis

${ }^{2}$ Fisher's exact test

supine scans. The proportion of patients with colons longer than $200 \mathrm{~cm}$ - between $6 \%$ and $11 \%$ - is roughly half the reported proportion of patients who have "difficult" colonoscopies, and may reflect potential looping problems rather than fixation or diverticulosis [25].

Comparing 20-mg to 40-mg IV hyoscine, there were no significant differences, suggesting that the lower dose is adequate to optimize visualization and decrease missed areas. Interestingly, the proportion of missed areas overall that occurred in the rectum and sigmoid $(20 \%-22 \%)$ was much less than might have been predicted from the proportion of the colonic length exam- ined (37\%-39\%), suggesting that missed areas are more common in the proximal colon, an area already known to be at higher risk for cancer misses and failed cancer prevention after colonoscopy [26, 27].

\section{Comparison with other studies}

The benefit of hyoscine butylbromide in improving adenoma and polyp detection have been reviewed in a recent meta-analysis, which reported a relative risk for adenoma detection of 1.09 (95\% confidence interval $0.91-1.31)$ and polyps $1.13(95 \%$ CI $0.92-1.38$ ) numerically but nonsignificantly in favor of hyo- 
scine [16], and in a very large cohort study $(n=31088)$ from the National Health Service bowel cancer screening program, the proportion of patients with at least one adenoma detected was $50.1 \%$ with hyoscine versus $44.5 \%$ without (relative increase $12.6 \%, P<0.001$ ) with similar improvements for advanced adenoma detection rates $27.4 \%$ vs $31.8 \%, P<0.001$. These differences persisted after correction for other variables. Therefore, the $4 \%$ increase in surface visualization seen in our study in the supine position, most representative of optical colonoscopy, might explain up to half the benefit for polyp detection seen in clinical studies in which a $9 \%$ to $13 \%$ relative increase is reported. The residual benefit may be due to having a still surface for polyp detection

Mean colonic length reported here, 161 to $169 \mathrm{~cm}$, is broadly similar to that seen in other studies assessing length with CTC, but is longer than the length reported in studies that used barium enema to assess colonic length, $145-155 \mathrm{~cm}[20,25,28]$.

One study has investigated the potentially adverse effects of hyoscine on hemodynamics at colonoscopy by giving larger doses ( $40 \mathrm{mg}$ ) to accentuate responses [6]. The relevance of these findings seems limited if such a large dose is unlikely to be needed clinically for optimal visualization, as suggested in the current study.

\section{Study limitations}

This study has a number of limitations. The original participants, whose data were analyzed further here, were recruited prospectively from outpatient clinics and had symptoms suggestive of colorectal cancer. Unfortunately only two-thirds of the dataset was available for review, making the current study less representative of the original population and possibly adding unknown bias, although data loss was random and groups remain well matched. As discussed above, the simulation represents a "straight pull-back" withdrawal technique where the colonoscopist attempts to keep the tip of the scope in the center of the lumen and withdraws slowly. In reality, colonoscopists use a more active withdrawal technique, which may increase the amount of colonic surface seen beyond that reported here. The data presented, therefore, should not be regarded as reflecting absolute percentage visualization at optical colonoscopy, but rather, a guide to likely effect sizes if spasmolysis were employed. We assumed that increased surface visualization leads to increased polyp detection, which is logical but unproven; however, recent data from a clinical trial that used a retrograde viewing auxiliary imaging device to improve surface visualization showed an overall increase in adenoma detection of $11.0 \%$, very similar to the predicted increase of $12.1 \%$ in surface visualization in a previous simulation of such a device using the current CTC simulation $[23,29]$. Although the simulation gives a quantitative measurement of effect size in terms of surface visualization and sizes of missed areas, antispasmodic has other effects. In particular, it reduces peristalsis, which immobilizes the surface visualized, and could potentially be as or more important than improvements in surface visualization.

\section{Clinical implications}

The current study would support the clinical use of hyoscine butylbromide to optimize colonoscopic visualization, but suggests that the effect size is modest; however, that may explain up to half the benefit reported for adenoma detection seen in clinical studies. The minimal cost involved (one 20-mg ampoule
Buscopan ${ }^{\circledR}$ for injection, £0.29, British National Formulary, 2015) for this modest benefit may be acceptable.

Overall the lack of change in colonic length seen in this study would argue against those who have concerns regarding antispasmodics increasing colonic length at colonoscopy. Excessive colonic length estimated by barium enema is known to predict difficult colonoscopy [30].

From our study data, it seems unlikely that there is likely to be further benefit from doses of hyoscine beyond $20 \mathrm{mg}$. We were not able to assess whether even smaller doses might give the same clinical benefit.

\section{Conclusions}

$\nabla$

In this anatomical simulation study of colonoscope withdrawal to examine the mechanism of benefit on adenoma detection, we found that IV administration of hyoscine butylbromide increased the percentage of colonic surface visualization by approximately $4 \%$, with a relative decrease of $20 \%$ in the number of clinically significant $\left(300-1000 \mathrm{~mm}^{2}\right)$ missed areas. This mechanism may explain up to half the improvement in adenoma and polyp detection seen in clinical studies.

Competing interests: Drs. Halligan and Taylor are NIHR senior investigators. No author has a conflict of interest related to this study

\author{
Institutions \\ ${ }^{1}$ Translational Gastroenterology Unit, University of Oxford, John Radcliffe \\ Hospital, Oxford, United Kingdom \\ 2 Wolfson Unit for Endoscopy, St. Mark's Hospital, Watford Road, Harrow, \\ Middlesex, HA1 3UJ, United Kingdom \\ ${ }^{3}$ Intestinal Imaging Centre, St. Mark's Hospital, Watford Road, Harrow, \\ Middlesex, HA1 3UJ, United Kingdom \\ ${ }^{4}$ Department of Specialist Radiology, University College Hospital, \\ 235 Euston Road, London, NW1 2BU, United Kingdom \\ ${ }^{5}$ Department of Radiology, Frimley Health NHS Foundation Trust, Wexham \\ Park Hospital, Wexham Street, Slough, Berkshire, SL2 4HL
}

\section{Acknowledgements \\ $\nabla$}

The authors wish to thank Viatronix, Stonybook, NY, for the software patches that made the current study possible, Lesley Honeyfield and Julian Tsang at Medicsight PLC, London, UK, for assistance with and use of their workstation, and Paul Bassett for statistical advice.

\section{References}

1 Barclay RL, Vicari JJ, Doughty AS et al. Colonoscopic withdrawal times and adenoma detection during screening colonoscopy. N Engl J Med 2006; 355: $2533-2541$

2 East JE, Suzuki N, Arebi N et al. Position changes improve visibility during colonoscope withdrawal: a randomized, blinded, crossover trial. Gastrointest Endosc 2007; 65: 263 - 269

3 Froehlich F, Wietlisbach V, Gonvers JJ et al. Impact of colonic cleansing on quality and diagnostic yield of colonoscopy: the European Panel of Appropriateness of Gastrointestinal Endoscopy European multicenter study. Gastrointest Endosc 2005; 61: 378 - 384

4 Rex D. Colonoscopic withdrawal technique is associated with adenoma miss rates. Gastrointest Endosc 2000; 51: 33 - 36

5 Saunders B, Williams C. Premedication with intravenous antispasmodic speeds colonoscope insertion. Gastrointest Endosc 1996; 43: $209-211$

6 Mui LM, Ng EK, Chan KC et al. Randomized, double-blinded, placebocontrolled trial of intravenously administered hyoscine N-butyl bro- 
mide in patients undergoing colonoscopy with patient-controlled sedation. Gastrointest Endosc 2004; 59: 22 - 27

7 Takahashi Y, Tanaka H, Kinjo $M$ et al. Prospective evaluation of factors predicting difficulty and pain during sedation-free colonoscopy. Dis Colon Rectum 2005; 48: 1295-1300

8 Shaheen NJ, Robertson DJ, Crosby MA et al. Hyoscyamine as a pharmacological adjunct in colonoscopy: a randomized, double blinded, placebo-controlled trial. Am Journal Gastroenterol 1999; 94: 2905-2908

9 Asao T, Mochiki E, Suzuki $H$ et al. An easy method for the intraluminal administration of peppermint oil before colonoscopy and its effectiveness in reducing colonic spasm. Gastrointest Endosc 2001; 53: 172 177

10 Bond JH, Chally CH, Blackwood WD. A controlled trial of premedication with dicyclomine hydrochloride (Bentyl) in colonoscopy. Gastrointest Endosc 1974; 21: 61

11 Cutler CS, Rex DK, Hawes $R H$ et al. Does routine intravenous glucagon administration facilitate colonoscopy? A randomized trial. Gastrointest Endosc 1995; 42: 346-350

12 Norfleet $R G$. Premedication for colonoscopy: randomized, doubleblind study of glucagon versus placebo. Gastrointest Endosc 1978; 24: $164-165$

13 Waxman I, Mathews J, Gallagher J et al. Limited benefit of atropine as premedication for colonoscopy. Gastrointest Endosc 1991; 37: 329 331

14 Church JM. Warm water irrigation for dealing with spasm during colonoscopy: Simple, inexpensive, and effective. Gastrointest Endosc 2002; 56: $672-674$

15 Pickhardt PJ, Nugent PA, Mysliwiec PA et al. Location of adenomas missed by optical colonoscopy. Ann Intern Med 2004; 141: 352 - 359

16 Rondonotti E, Zolk O, Amato A et al. The impact of hyoscine-N-butylbromide on adenoma detection during colonoscopy: meta-analysis of randomized, controlled studies. Gastrointest Endosc 2014; 80: 1103 1112

17 Lee TJ, Rees CJ, Blanks RG et al. Colonoscopic factors associated with adenoma detection in a national colorectal cancer screening program. Endoscopy 2014; 46: 203-211
18 Bowles CJA, Leicester R, Romaya C et al. A prospective study of colonoscopy practice in the UK today: are we adequately prepared for national colorectal cancer screening tomorrow? Gut 2004; 53: 277-283

19 Rex DK, Bond JH, Winawer S et al. Quality in the technical performance of colonoscopy and the continuous quality improvement process for colonoscopy: recommendations of the U.S. Multi-Society Task Force on Colorectal Cancer. Am J Gastroenterol 2002; 97: 1296-1308

20 Rogalla P, Lembcke A, Ruckert JC et al. Spasmolysis at CT colonography: Butyl scopolamine versus glucagon. Radiology 2005; 236: 184-188

21 Taylor SA, Halligan S, Goh Vet al. Optimizing colonic distention for multi-detector row CT colonography: Effect of hyoscine butylbromide and rectal balloon catheter. Radiology 2003; 229: 99-108

22 Goei R, Nix M, Kessels AH et al. Use of antispasmodic drugs in double contrast barium enema examination: glucagon or buscopan? Clin Radiol 1995; 50: 553 - 557

23 East JE, Saunders BP, Burling D et al. Surface visualisation at CT colonography simulated colonoscopy: Effect of varying field of view and retrograde view. Am J Gastroenterol 2007; 102: 2529-2535

24 Pickhardt PJ, Taylor AJ, Gopal DV. Surface visualization at 3D endoluminal CT colonography: Degree of coverage and implications for polyp detection. Gastroenterology 2006; 130: 1582 - 1587

25 Saunders B, Fukumoto M, Halligan $S$ et al. Why is colonoscopy more difficult in women? Gastrointest Endosc 1996; 43: 124-126

26 Bressler B, Paszat LF, Chen Z et al. Rates of new or missed colorectal cancers after colonoscopy and their risk factors: A population-based analysis. Gastroenterology 2007; 132: 96-102

27 Baxter NN, Goldwasser MA, Paszat LF et al. Association of colonoscopy and death from colorectal cancer. Ann Intern Med 2009; 150: 1-8

28 Khashab MA, Pickhardt PJ, Kim DH et al. Colorectal anatomy in adults at computed tomography colonography: normal distribution and the effect of age, sex, and body mass index. Endoscopy 2009; 41: 674-678

29 Waye JD, Heigh RI, Fleischer DE et al. A retrograde-viewing device improves detection of adenomas in the colon: a prospective efficacy evaluation (with videos). Gastrointest Endosc 2010; 71: 551 - 556

30 Saunders BP, Halligan S, Jobling $C$ et al. Can barium enema indicate when colonoscopy will be difficult? Clin Radiol 1995; 50: 318-321 